\title{
Six years after repair of a giant ascending aortic aneurysm
}

\author{
Khaled E. Al-Ebrahim, FRCSC
}

A 34-year-old man was seen with extreme shortness of breath. Echocardiography showed aortic aneurysm, severe aortic regurgitation, and poor left ventricular function. Chest computed tomography revealed a $13-\mathrm{cm}$ wide ascending aortic aneurysm (Figure 1).The aneurysm involved all the sinuses of Valsalva, causing cephalad displacement

From the Department of Cardiothoracic Surgery, King Abdulaziz University Hospital, Jeddah, Saudi Arabia.

Disclosures: Author has nothing to disclose with regard to commercial support.

Received for publication March 28, 2012; accepted for publication April 5, 2012; available ahead of print Sept 14, 2012.

Address for reprints: Khaled E. Al-Ebrahim, FRCSC, Department of Surgery, King Abdulaziz University Hospital, PO Box 80215, Jeddah 21589, Saudi Arabia (E-mail: Dr.k-e@hotmail.com).

J Thorac Cardiovasc Surg 2012;144:1254-5

$0022-5223 / \$ 36.00$

Copyright (c) 2012 by The American Association for Thoracic Surgery http://dx.doi.org/10.1016/j.jtcvs.2012.04.023

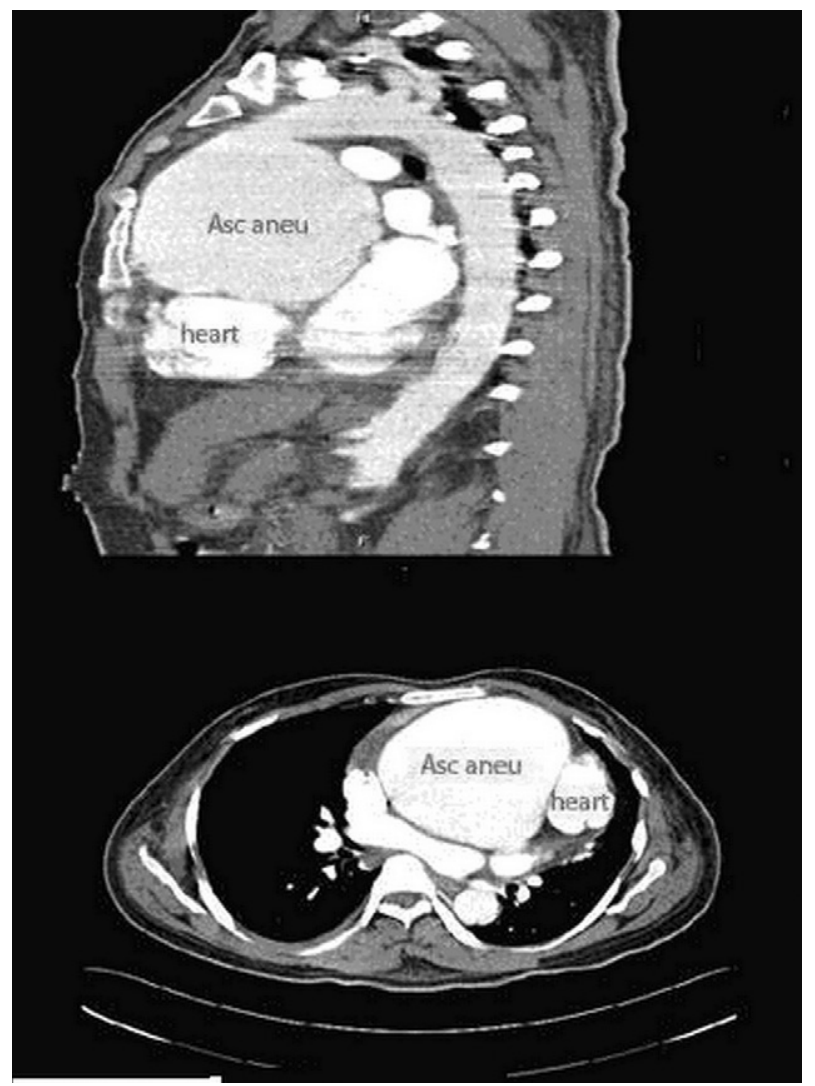

FIGURE 1. Top, Preoperative computed tomographic image showing the 13-cm ascending aortic aneurysm (Asc aneu), larger than the heart. The neck of the aneurysm was before aortic branching; this positioning facilitating central cannulation and clamping. Bottom, Preoperative computed tomographic image illustrating how much larger the huge ascending aortic aneurysm was than the heart.

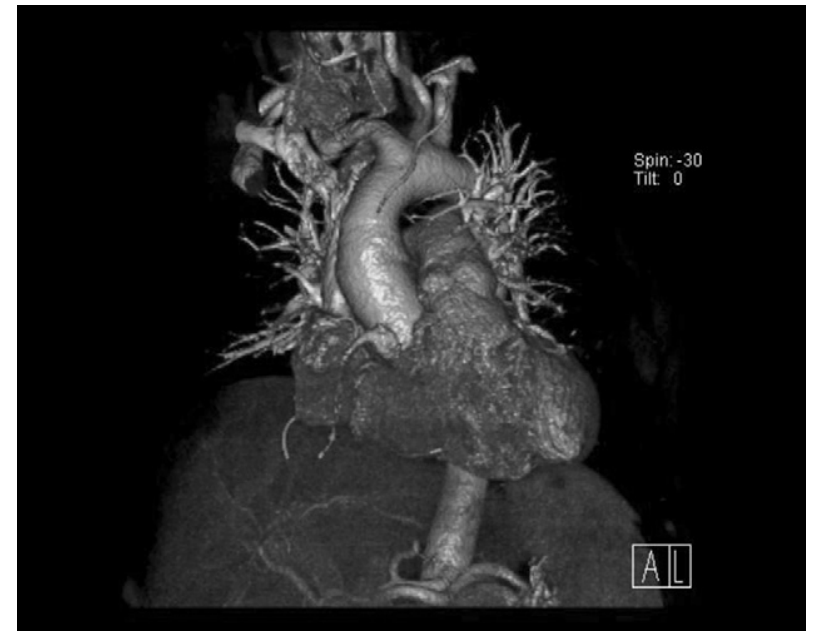

FIGURE 2. Postoperative 3-dimensional reconstructed computed tomographic image showing the Dacron polyester fabric graft and the right coronary artery.

of the coronary ostia. With central cannulation and retrograde coronary sinus cardioplegia, a size 31 composite graft was sewn to the aortic root with multiple pledgeted 2-0 sutures. The left and right coronary ostia were buttoned and anastomosed to the appropriate sites in the Dacron polyester fabric graft with 7-0 monofilament sutures. This patient has been followed up for longer than 6 years with no complications and is leading a nearly normal life with dramatic improvement in ejection fraction and renal function (Figures 2-4). This is the largest ascending aortic aneurysm reported to date in the literature.

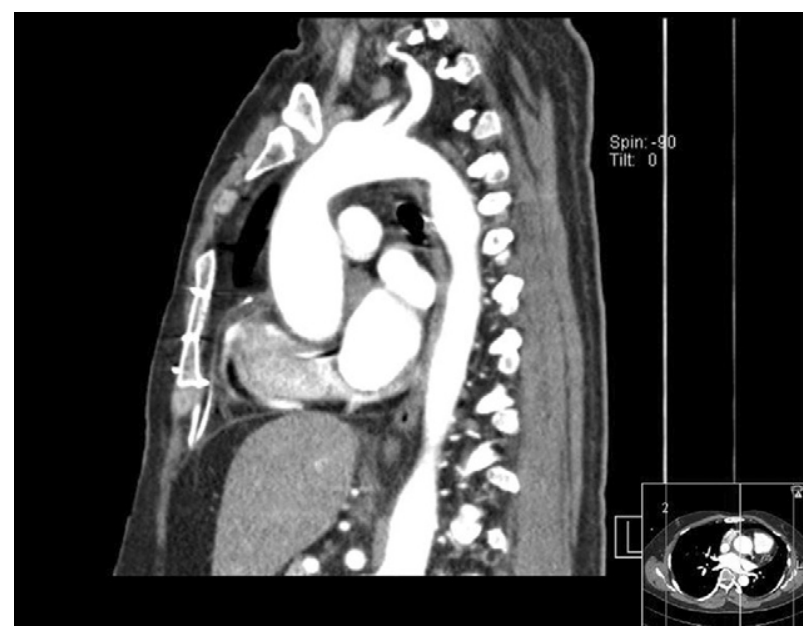

FIGURE 3. Sagittal section of the composite graft. 


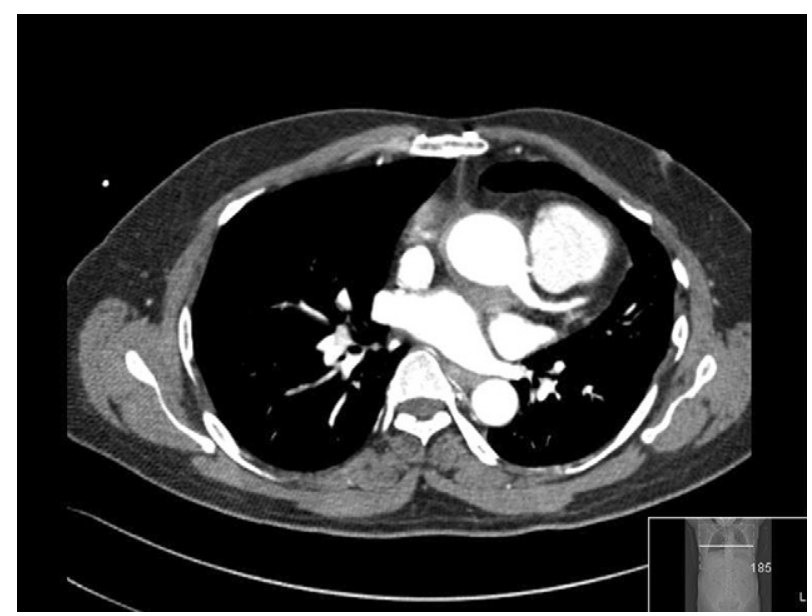

FIGURE 4. Cross section showing the left coronary artery. 